\title{
PERSPECTIVES
}

\section{Leveraging Primary Care in the Fight Against Lung Cancer}

\author{
Jason L. Sanders, $B A^{1,3}$ and Yolonda L. Colson, MD, PhD ${ }^{2,3}$ \\ 'Division of Thoracic Surgery, Department of Surgery, Brigham and Women's Hospital, Boston, MA, USA; ${ }^{2}$ Department of Surgery, Harvard \\ Medical School, Harvard University/Brigham and Women's Hospital, Boston, MA, USA; 'Women's Lung Surgery Program, Fish Center for \\ Women's Health, Brigham and Women's Hospital, Boston, MA, USA.
}

In recent years, the decline in youth smoking rates has stopped as the tobacco industry strives to successfully reclaim market areas where it has lost favor. The plateau in lung cancer incidence and stagnation in progress toward smoking abstinence illustrates the necessity for renewed efforts to fight tobacco use. Barriers to fighting tobacco use exist in both the clinical arena and within the general population, but can be overcome. Primary care physicians (PCPs) are uniquely poised to successfully treat nicotine dependence with strategic targeting of these barriers, improved training in smoking cessation techniques, and focused political efforts in tobacco control. Herein, this article describes the landscape of tobacco use in America and provides background, methodology, and resources for PCPs to help achieve the goals of Healthy People 2010 in reducing the illness, disability, and death that occur as a result of tobacco use and exposure to secondhand smoke.

KEY WORDS: primary care; lung cancer; tobacco control;

smoking cessation.

J Gen Intern Med 23(3):344-7

DOI: $10.1007 / \mathrm{s} 11606-007-0493-9$

(c) Society of General Internal Medicine 2007

\section{INTRODUCTION}

"Hot-pink fuchsia...minty-green teal...light and luscious...premium and sophisticated" ${ }^{1}$. This is not a travel agent's tagline to lure college coeds to the hottest Caribbean resort for spring break. Rather, it is the latest incarnation of RJ Reynolds' methods to get young women hooked on cigarettes. In American nightclubs, Reynolds American is distributing free samples of their Camel No. 9 while filling the pages of Vogue, Glamour, W, Cosmopolitan, and Flaunt with ads for this new cigarette. Cressida Lozano, vice president for marketing of the Camel brand, explained Reynolds wants to "focus on products that are 'wow,'... that add fun and excitement to the [female cigarette] category". ${ }^{1}$ By virtue of their advertising campaign, Reynolds is targeting young women who require a "wow" factor to initiate smoking. When "wow" is replaced by premature aging, chronic

Received June 27, 2007

Revised November 20, 2007

Accepted December 6, 2007

Published online January 3, 2008 cough, and wheezing, the nicotine addiction will be enough to keep most from quitting. After a few decades of smoking "sophisticated" cigarettes, some of these young women will unfortunately join the nearly 170,000 Americans that die of lung cancer each year-deaths that could be readily prevented by successful anti-smoking interventions. ${ }^{2}$ By learning the personal and political barriers to smoking abstinence and improved techniques to treat nicotine dependence, primary care physicians (PCPs) can serve as the foundation for a strong campaign countering tobacco use. This article offers the knowledge and tools that PCPs require to significantly impact the prevalence of smoking and the number of lung cancer deaths in this country.

\section{PHYSICIAN BARRIERS TO PROGRESS IN SMOKING CESSATION}

\section{Psychosocial and Training Barriers}

Physicians can most directly impact the prevalence of smoking by encouraging their patients to remain or become smokefree. The US Public Health Service (USPHS) recommends that physicians use the " $5 \mathrm{~A}$ process" to help patients quit smoking: 1) Ask every patient about tobacco use, 2) Advise all smokers to quit, 3) Assess smokers' willingness to make a quit attempt, 4) Assist smokers with treatment and referrals, and 5) Arrange follow-up contacts. Asking: Asking a patient's smoking status is sometimes forgotten. ${ }^{3}$ PCPs have little time during a patient's visit and acute concerns are dealt with more often than enumerating lifestyle factors. Whereas most PCPs ask about a patient's smoking status, all physicians should remember to ask at every routine visit. ${ }^{3}$ Advise and Assess: Once a patient is identified as a smoker, advising cessation and assessing willingness to quit are not challenging. A physician can stress the negative health effects of smoking without belaboring them and simply ask, "Do you want to quit? Do you think you could quit now?" However, assessing willingness is often hindered by the PCP's perception of the patient's lack of motivation to quit or by the PCP's own insecurities about helping with cessation. ${ }^{4}$ If a patient is positive about quitting, the PCP's job is easier, but even a patient who thinks quitting will be difficult can be helped by building a patient's confidence through a persistent positive outlook. Quit rates increase by $120 \%$ when continued physician involvement is present versus no involvement. ${ }^{5}$ It is important to emphasize that cessation does not happen overnight. Assisting and Arranging: Where physicians fail most often is in offering assistance and continued reinforcement through arranged follow-up, often from lack of training and comfort on the 
part of the physician. Education focused on preventative medicine and smoking cessation is shortchanged in medical school curricula and is often not stressed throughout a physician's lifelong learning. Medical school curricula do not reflect the most current knowledge of tobacco dependence, intervention training, and cultural issues of tobacco use, and must be revised accordingly. ${ }^{6}$ Interactive programs such as tobacco-specific standardized patient instructors have been highly rated by medical students in trial programs and successfully expand students' knowledge of cessation techniques and clinical competency. ${ }^{7}$ Similar success has been achieved with web-based courses, and may be applicable to practicing physicians as well. ${ }^{8}$ Not surprisingly, PCPs with specific training in smoking cessation do achieve greater, sustained quit rates compared to physicians without such training. ${ }^{9}$ To produce physicians capable of assisting smokers, medical schools must augment their curricula to include smoking cessation training and professional organizations must encourage and provide opportunities to earn CME credit through subsidized cessation courses.

A trained, enabled PCP has many treatment options that can help assist a smoker to quit. Pharmacotherapies for nicotine dependence have markedly improved in recent years. Recent Cochrane Database reviews have noted pooled odds ratios (OR) of 3.22 (95\% confidence interval [CI] 2.43-4.27) for continuous abstinence at 12 months using varenicline, a new agent that binds centrally to the $\alpha 4 \beta 2$ nicotinic acetycholine receptor to provide both agonist and antagonist effect, versus placebo, and 1.66 (95\% CI 1.28-2.16) for varenicline versus bupropion. ${ }^{10}$ Bupropion, which acts as a norepinephrine and dopamine reuptake inhibitor and nicotine antagonist, increases quit rates by 94\% (95\% CI 1.72-2.19) and nortriptyline by $134 \%$ (95\% CI 1.61-3.41) versus placebo. ${ }^{11}$ As an important adjunct to any pharmacotherapy, PCPs should also refer smokers to other resources, such as telephone quitlines. Quitlines can provide more frequent contact and circumvent the limited time a PCP has during a visit to offer cessation counseling. Among smokers who contacted quitlines, cessation rates are higher for groups receiving multiple sessions of call-back counseling (OR 1.41, 95\% CI 1.27-1.57). Telephone counseling not initiated by calls to helplines also increases long-term cessation (OR 1.33, 95\% CI $1.21-1.47)^{12}$. Behavioral therapy either in the form of group or individual counseling can also be suggested as group programs achieve higher quit rates compared to individual therapy (OR $2.04,95 \%$ CI 1.60-2.60) or no intervention (OR 2.17, 95\% CI 1.37-3.45), although there is no evidence that group therapy is more effective than a similar intensity of individual counseling. ${ }^{13}$ After assisting a patient, a PCP can remain active throughout the cessation process by helping the patient choose a quit deadline, providing praise for improvement or more intense therapy and encouragement after relapse, and recommending frequent office visits to promote accountability. (For the complete USPHS clinical practice guidelines for treating tobacco use and dependence, see "Resources" at www.endsmoking.org.)

\section{Financial Barriers}

PCPs are often disinclined to provide cessation intervention because of low or no reimbursement. Fortunately, the Professional Assisted Cessation Therapy (PACT) consortium offers a comprehensive, up-to-date, and concise guide for maximizing reimbursement for providing cessation therapy. ${ }^{14}$ Reimbursement for Smoking Cessation Therapy: A Healthcare Practitioner's
Guide outlines the language of smoking cessation treatment and health benefit coverage options, how to obtain reimbursement, and strategies and information that providers and clinic managers can use to enact change inside managed care organizations. Briefly stated, physicians and their staff must first be well versed in the lexicon of smoking cessation. They should know which conditions they can provide smoking cessation therapy for in the context of a regular visit, and the proper reimbursement code for cessation depending on the condition it is provided for. It is crucial to be aware of the national, state, local, and private sources of reimbursement including Medicare, Medicaid, managed care organizations (MCOs), employer and employee purchasing coalitions, tobacco settlement initiatives, and pharmaceutical company-sponsored programs. Once physicians and office managers have these data at their disposal, they can work within MCOs and the legislative realm to achieve higher reimbursement, provided they can illustrate the utility of smoking cessation. The Guide provides information on all of these aspects of obtaining reimbursement and provides additional references.

\section{POPULATION BARRIERS TO SMOKING CESSATION}

Smoking cessation does not exist in a vacuum. Whereas PCPs can help current smokers quit and encourage non-smokers to stay smoke-free, they face population-level barriers to reducing the prevalence of smoking. Recent reports from the Centers for Disease Control and Prevention (CDC) reveal that 54.3\% of high school students have, at some time, tried smoking and $23 \%$ are regular smokers. ${ }^{15}$ It is alarming that tobacco marketing dollars increased $123 \%$ between 1998 and 2003. ${ }^{16}$ From 2002 to 2003 , the tobacco industry spent $\$ 15.15$ billion on advertising and marketing, an increase of $\$ 2.68$ billion (21.5\%) from the previous year and the largest increase since the Federal Trade Commission began recording such spending in $1967^{17}$ (Fig. 1). Despite this increase in marketing dollars, the government has shown a poor commitment to prevention. In fiscal year 2007, state governments expect to accrue \$21.7 billion in revenue from Masters Settlement Agreement payments, tobacco excise taxes, and other tobacco-related sources,

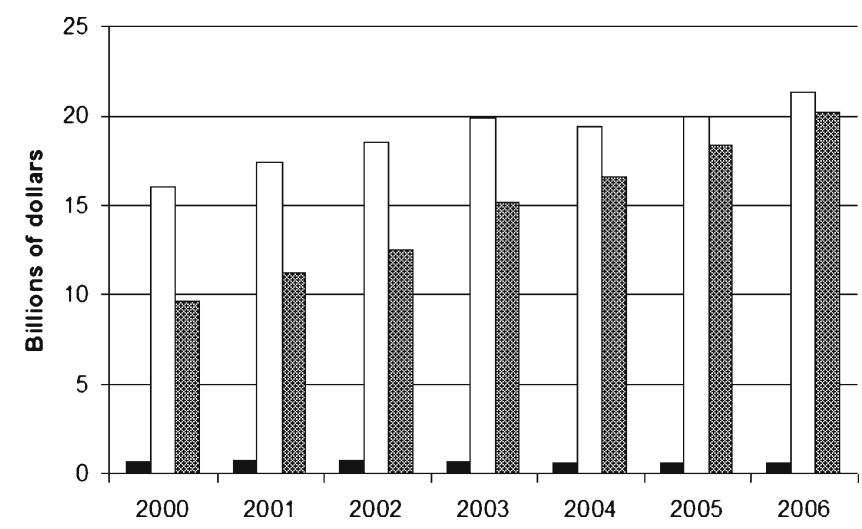

Figure 1. Total state government expenditures on tobacco prevention, state government tobacco revenues, and tobacco industry marketing expenditures. Industry marketing expenditures from 2004 to 2006 are estimated with linear regression. State, as opposed to federal, expenditures on prevention are shown in black, state revenues in white, and industry marketing expenditures in checked bars. (Data from references 16 and 17.) 
but have allotted only $\$ 597.5$ million of state funds for tobacco prevention, or $2.8 \%$ of revenues (Fig. 1). The $\$ 595.5$ million represents only $37 \%$ of the CDC-recommended $\$ 1.6$ billion that state governments are advised to spend toward tobacco prevention. Only 4 states have met the CDC's state-specific minimum financial recommendations for youth tobacco control program spending, 35 states failed to meet half of their recommended spending level, and some states have even decreased prevention dollars in recent years. ${ }^{16}$ It is therefore not surprising that in the wake of the greatest spending ever by the tobacco industry, the decline in youth smoking seen during the mid-1990s has slowed, and as of 2003 that decline has stopped. ${ }^{18}$

What are the skills PCPs need to help counteract these trends? Knowledge of the legislative process is paramount. A concise article to help physicians navigate politics is "Seven tips for effecting legislative change". ${ }^{19}$ Physicians should get to know their local legislator, actively support or oppose proposed legislation, serve on task forces, and advocate for state funding to implement tobacco control measures. ${ }^{19}$ Physicians can also be effective by speaking in the legislature, being sure to avoid medical jargon, know the pros and cons of the issue, learn the legislative process, be truthful about the lack of knowledge on certain issues, and remain patient with the process. ${ }^{19}$ PCPs provide an important body of knowledge particularly relevant to enacting preventive measures on a population level. Their words add credibility to a bill. By introducing legislation and speaking on the floor, PCPs visibly reinforce their commitment to their community and can serve as leaders for patients and as tobacco control advocates. A more comprehensive guide for physicians is the Physicians' Guide to State Legislation published by the American College of Emergency Physicians, which provides background, methodology, and case studies regarding how physicians can bring about legislative change. ${ }^{20}$ This resource includes examples of successful physician-driven legislative campaigns to build a motorcycle helmet safety coalition, ensure adequate Medicaid reimbursement for emergency care, increase funding for physician education, and augment MCO payment to providers, as well as failed attempts at legislation such as limiting the sale of assault weapons. ${ }^{20}$ These case studies provide transferable skills and processes, such as outlining a problem, organizing allied groups, approaching the legislature, gaining political allies, defending one's stances against the opposition, and maintaining success during appeals. PCPs can use these skills to effectively combat tobacco on a population level.

Once PCPs know how to be effective agents of political change, there are many legislative issues related to tobacco that physicians should address-both in terms of prevention and cessation. More of the Master's Settlement Agreement funds and tobacco revenue must be spent on prevention. ${ }^{16}$ Physicians can introduce and support bills that call for a greater percentage of this money to be earmarked for tobacco control. Outlets for spending include counter-advertising to directly combat tobacco marketing, financing public quitlines, smoking cessation clinics, and physician education in smoking cessation, and increasing provider reimbursement for counseling and cessation therapy. A particularly important goal should be to achieve widespread Medicaid coverage of tobacco-dependence therapies. In 2006, $35 \%$ of Americans covered by Medicaid alone were current smokers versus $18 \%$ of those privately insured. ${ }^{21}$ An analysis of USPHS-recommended system-wide strategies to combat tobacco-dependence examined whether state Medicaid pro- grams supported at least 4 of the 6 recommended system-wide strategies, and found that more than half of state Medicaid programs (27 states) covered 1 or no strategies. ${ }^{22}$ This leaves low-income smokers at risk for lung cancer and other tobaccorelated illnesses, and coverage should be expanded to protect this especially vulnerable group. As of October 1, 2007, more than 2,600 municipalities have passed laws that restrict smoking in certain areas and 11,305 municipalities have enacted $100 \%$ smoke-free laws (www.no-smoke.org), covering approximately $58.6 \%$ of the US population. ${ }^{23}$ Analysis of pre and postsmoking ban business revenue has consistently revealed no negative impact on profits made by restaurants, bars, hotels, and general tourism establishments. ${ }^{24-27}$ Increasing tobacco taxes will negatively impact tobacco sales, especially to adolescents, and produce more money for tobacco prevention. ${ }^{28}$ Ending the Tobacco Problem: A Blueprint for the Nation is a road map for America to irreversibly commit to ending the tobacco epidemic and can serve as a wealth of information for physicians hoping to fight tobacco on a community or national level. ${ }^{29}$

\section{CONCLUSION}

One goal of Healthy People 2010 is to reduce illness, disability, and death related to tobacco use and exposure to secondhand smoke. In 2006, the National Institutes of Health convened an expert panel to evaluate the state of the science on tobacco use in America. The panel concluded that, "Coordinated national strategies for tobacco prevention, cessation, and control are essential if the United States is to achieve the Healthy People 2010 goals. Most adult smokers want to quit, and effective interventions exist. However, only a small proportion of tobacco users try treatment. Many cities and states have implemented effective policies to reduce tobacco use; public health and government leaders should learn from these experiences". ${ }^{30}$ PCPs are poised to intervene at every level to achieve these goals if improvements are made to overcome the barriers to progress outlined above. With proper training and resources, PCPs can serve as integral members of a successful, broad, united front against tobacco.

Acknowledgments: Author Contributions: YLC (conception and design; analysis and interpretation of data; drafting of the manuscript; critical revision of the manuscript for important intellectual content; supervision); JLS (conception and design; acquisition of data; analysis and interpretation of data; drafting of the manuscript; critical revision of the manuscript for important intellectual content; administrative support)

Financial Disclosures: None

Potential Conflicts of Interest: None disclosed.

Corresponding Author: Yolonda L. Colson, $M D, P h D$; Brigham and Women's Hospital, 75 Francis Street, PBB5, Boston, MA 02115, USA (e-mail: ylcolson@ bics.bwh.harvard.edu).

\section{REFERENCES}

1. Eliot S. A new camel brand is dressed to the nines. New York Times Online. February 15, 2007; Business. Accessed June 2, 2007. 
2. Jemal A, Siegel, Ward E. Cancer statistics, 2006. CA Cancer J Clin. 2006;56(2): 106-30. Mar Apr.

3. Schnoll RA, Rukstalis M, Wileyto EP, Shields AE. Smoking cessation treatment by primary care physicians: an update and call for training. Am J Prev Med. 2006;31(3):233-239.

4. Coleman T, Wilson A. Anti-smoking advice in general practice consultations: general practitioners' attitudes, reported practice and perceived problems. Br J Gen Pract. 1996;46(403):87-91.

5. Fiore MC, Bailey WC, Cohen SJ. Treating tobacco use and dependence. Clinical Practice Guideline. Rockville, MD: U.S. Department of Health and Human Services, Public Health Service; June 2000 .

6. Spangler JG, George G, Foley KL, Crandall SJ. Tobacco intervention training: current efforts and gaps in US medical schools. JAMA. 2002; 288(9): 1102-1109.

7. Foley KL, George G, Crandall SJ, Walker KH, Marion GS, Spangler JG. Training and evaluating tobacco-specific standardized patient instructors. Fam Med. 2006;38(1):28-37.

8. Pederson LL, Blumenthal DS, Denver A, McGrady G. A web-based smoking cessation and prevention curriculum for medical students: why, how, what, and what next. Drug Alcohol Rev. 2006;25(1):3947.

9. Katz DA, Muehlenbruch D, Brown RL. Effectiveness of implementing the agency for healthcare research and quality smoking cessation clinical practice guideline: a randomized, controlled trial. J Natl Cancer Inst. 2004;96(8):594-603.

10. Cahill K, Stead LF, Lancaster T. Nicotine receptor partial agonists for smoking cessation. Cochrane Database of Systematic Reviews. 2007; Issue 1. Art. No.:CD006103.

11. Hughes JR, Stead LF, Lancaster T. Antidepressants for smoking cessation. Cochrane Database of Systematic Reviews. 2007; Issue 1. Art. No.:CD000031.

12. Stead LF, Perera R, Lancaster T. Telephone counselling for smoking cessation. Cochrane Database of Systematic Reviews. 2006; Issue 3. Art. No.:CD002850.

13. Stead LF, Lancaster T. Group behaviour therapy programmes for smoking cessation. Cochrane Database of Systematic Reviews. 2005; Issue 2. Art. No.:CD001007.

14. Professional Assisted Cessation Therapy. Reimbursement for smoking cessation therapy: a healthcare practitioner's guide, 3rd Edition. Available at: http://www.endsmoking.org/resources/reimbursementguide/ pdf/reimbursementguide-3rd-edition.pdf. Accessed October 20, 2007.

15. Cigarette use among high school students-United States, 19912005. MMWR Morb Mortal Wkly Rep. 2006;55(26):724-6.
16. Campaign for Tobacco-Free Kids. A broken promise to our children: The 1998 State Tobacco Settlement seven years later. Campaign for tobaccofree kids. Available at: www.tobaccofreekids.org/reports/settlements/ 2006/fullreport.pdf. Accessed June 2, 2007.

17. Federal Trade Commission Cigarette Report for 2003. Washington, DC: Federal Trade Commission; 2005.

18. Gritz E, Prokhorov AV, Hudmon KS. Predictors of susceptibility to smoking and ever smoking: a longitudinal study in a triethnic sample of adolescents. Nicotine Tob Res. 2003;5(4):493-508.

19. Hofford RA. Seven tips for effecting legislative change. Fam Pract Manag. 2001;8(4):35-8. April.

20. American College of Emergency Physicians. Physicians' guide to state legislation. 3rd EditionDallas, TX: American College of Emergency Physicians; 1997

21. Pleis J, Lethbridge-Cejku M. Summary health statistics for U.S. adults: National Health Interview Survey, 2006. National Center for Vital Health Statistics.. Vit Health Stat. 2007;10(235):1-21.

22. Bellows NM, McMenamin SB, Halpin HA. Adoption of system strategies for tobacco cessation by state Medicaid programs. Med Care. 2007;45 (4):350-356.

23. Overview list-how many smokefree laws? American Nonsmokers' Rights Foundation. 2007. Available at: http://www.no-smoke.org/pdf/mediaordlist. pdf. Accessed October 20, 2007.

24. Assessment of the impact of a $100 \%$ smoke-free ordinance on restaurant sales-West Lake Hills, Texas, 1992-1994. MMWR Morb Mortal Wkly Rep. 1995;44(19):370-2, May 19.

25. Glantz SA, Smith LR. The effect of ordinances requiring smoke-free restaurants and bars on revenues: a follow-up. Am J Public Health. 1997;87(10): 1687-1693.

26. Glantz SA. Effect of smokefree bar law on bar revenues in California. Tob Control. 2000;9(1):111-112.

27. Glantz SA, Charlesworth MA. Tourism and hotel revenues before and after passage of smoke-free restaurant ordinances. JAMA. 1999;281 (20):1911-1918.

28. Eriksen MP. Best practices for comprehensive tobacco control programs: opportunities for managed care organizations. Tobacco Control. 2000;9 (Suppl 1):I11-14.

29. Institute of Medicine. Ending the tobacco problem: a blueprint for the nation. Washington, DC: The National Academy of Sciences; 2007Available at: http://www.americanlegacy.org/Files/tobacco_final_report.pdf. Accessed October 21, 2007.

30. NIH State-of-the-Science Conference Statement on Tobacco Use: Prevention, Cessation, and Control. Ann Intern Med. 2006;145:839-844. 